\title{
SEVERE DELIRIUM FOLLOWING SINGLE DOSE OF TRAMADOL
}

Sir,

Given the volume of use of analgesic preparations with approved indications for acute pain, a number of drug interactions including less well-known and potentially clinically significant drug-drug interactions are increasingly being reported. ${ }^{[1]} \mathrm{A}$ 32-yearold male on treatment for cysticercosis was receiving Tab. albendazole, phenytoin, steroids and ranitidine. Meanwhile, the patient developed allergic rhinitis, fever, body and joint pain. His general and systemic examination was normal. He was started on cetrizine for allergy and tramadol for body and joint pain. There was no concomitant use of antidepressants. The patient continued to receive Tab. albendazole and oral steroid without any change in dosage. After 6 hours

he developed violent behavior and delirium. There were no myoclonic twitches or muscular rigidity. On examination he had tachycardia and excessive sweating. Pupils were bilateral $3 \mathrm{~mm}$ in size? and reacting to light. Bowel and bladder functions were normal. Blood investigations showed raised erythrocyte sedimentation rate, blood urea and serum creatinine were normal. Facilities for estimation were not available. The abnormal behavior could be controlled with haloperidol and both the drugs (tramadol and cetrizine) were discontinued. The Naranjo score ${ }^{[2]}$ for adverse drug reaction was 9 . There was no history of any significant illness prior to cysticercosis and he was not an alcoholic. He responded well and recovered completely. Although tramadol may represent a well-established, safe therapy for pain, ${ }^{[3-5]}$ abuse and dependence on tramadol as well as tramadol-related deaths have been increasingly reported, either when the drug is ingested alone or taken in combination with other potentially interactive drugs. ${ }^{[5-7]}$ Mild and transient central nervous system stimulation during therapy with tramadol has been reported in $7 \%$ of patients in clinical trials. ${ }^{[7]}$ The debilitating reaction following a single oral dose of tramadol may include ataxia, dilation of the pupils, numbness, tremulousness, and dysphoria lasting for hours and disappearing after discontinuation of the therapy. ${ }^{[7]}$ Rarely may it lead to fluctuating confusion and cognitive deficits (reversible after discontinuation of the drug). ${ }^{[8]}$ The exact mechanism of the adverse response is not known; however, based on phenotyping results, it has been suspected that it may be related to high concentrations of the active O-desmethyl metabolite of tramadol. ${ }^{[7]}$ 
AMIT AGRAWAL, S. K. DIWAN',

RAJESH MAHAJAN ${ }^{2}$

Departments of Surgery, ${ }^{1}$ Medicine and

${ }^{2}$ Anesthesiology, Datta Meghe Institute of Medical

Sciences, Sawangi (Meghe), Wardha, India

Correspondence:

Dr. Amit Agrawal,

Division of Neurosurgery,

Datta Meghe Institute of Medical Sciences, Sawangi, Meghe, Wardha- 442 004, Maharashtra, India. E-mail: dramitagrawal@gmail.com

\section{REFERENCES}

1. Hersh EV, Pinto A, Moore PA. Adverse drug interactions involving common prescription and over-the-counter analgesic agents. Clin Ther 2007;29:2477-97.

2. Naranjo CA, Busto U, Sellers EM, Sandor P, Ruiz I, Roberts EA, et al. A method for estimating the probability of adverse drug reactions. Clin Pharmacol Ther 1981;30:239-45.

3. Keskinbora K, Aydinli I. An atypical opioid analgesic: Tramadol. Agri 2006;18:5-19.

4. Pascual ML, Fleming RR, Gana TJ, Vorsanger GJ. Open-label study of the safety and effectiveness of long-term therapy with extended-release tramadol in the management of chronic nonmalignant pain. Curr Med Res Opin 2007;23:2531-42.

5. Wang HX, Wang L, Guan DW, Wang MB. Tramadol intoxication and its toxicological effect Article in Chinese]. Fa Yi Xue Za Zhi 2008;24: 293-6.

6. Ripple MG, Pestaner JP, Levine BS, Smialek JE. Lethal combination of tramadol and multiple drugs affecting serotonin. Am J Forensic Med Pathol 2000;21:370-4.

7. Gleason PP, Frye RF, O'Toole T. Debilitating reaction following the initial dose of tramadol. Ann Pharmacother 1997;31:1150-2.

8. Künig G, Dätwyler S, Eschen A, Schreiter Gasser $U$. Unrecognised long-lasting tramadol-induced delirium in two elderly patients: A case report. Pharmacopsychiatry 2006;39:194-9. 